\title{
Nuclear Expression of Hepatitis B Virus X Protein Is Associated with Recurrence of Early-Stage Hepatocellular Carcinomas: Role of Viral Protein in Tumor Recurrence
}

Jing Jin · Hae Yoen Jung · Kyu Ho Lee Nam-Joon $\mathrm{Yi}^{1} \cdot$ Kyung-Suk Suh ${ }^{1}$ Ja-June Jang · Kyoung-Bun Lee

Departments of Pathology and ${ }^{1}$ Surgery, Seoul National University College of Medicine Seoul, Korea

Received: September 30, 2015

Revised: March 12, 2016

Accepted: March 18, 2016

\section{Corresponding Author}

Kyoung-Bun Lee, MD, PhD

Department of Pathology, Seoul National University Hospital, 101 Daehak-ro, Jongno-gu, Seoul 03080, Korea

Tel: +82-2-2072-2968

Fax: $+82-2-743-5530$

E-mail:kblee@snuh.org
Background: Hepatitis B virus (HBV) plays well-known roles in tumorigenesis of hepatocellular carcinoma (HCC) in infected patients. However, HBV-associated protein status in tumor tissues and the relevance to tumor behavior has not been reported. Our study aimed to examine the expression of HBV-associated proteins in HCC and adjacent nontumorous tissue and their clinicopathologic implication in HCC patients. Methods: HBV surface antigen (HBsAg), HBV core antigen $(\mathrm{HBCAg})$, and HBV X protein $(\mathrm{HBX})$ were assessed in $328 \mathrm{HBV}$-associated HCCs and in 155 matched nontumorous tissues by immunohistochemistry staining. Results: The positive rates of $\mathrm{HBsAg}$ and cytoplasmic $\mathrm{HBx}$ staining in tumor tissue were lower than those in nontumorous tissue $(7.3 \%$ vs. $57.4 \%, p<.001 ; 43.4 \%$ vs. $81.3 \%, p<.001)$. Conversely, nuclear HBx was detected more frequently in tumors than in nontumorous tissue ( $52.1 \%$ vs. $30.3 \%, p<.001)$. HCCs expressing $\mathrm{HBsAg}, \mathrm{HBcAg}$, or cytoplasmic $\mathrm{HBx}$ had smaller size; lower Edmondson-Steiner (ES) nuclear grade, pT stage, and serum alpha-fetoprotein, and less angioinvasion than HCCs not expressing HBV-associated proteins. Exceptionally, nuclear HBx-positive HCCs showed higher ES nuclear grade and more frequent large-vessel invasion than did nuclear HBx-negative HCCs. In survival analysis, only nuclear HBx-positive HCCs had shorter disease-free survival than nuclear HBx-negative HCCs in pT1 and ES nuclear grade 1-2 HCC subgroup (median, 126 months vs. 35 months; $\mathrm{p}=.015)$. Conclusions: Our data confirmed that expression of normal HBV-associated proteins generally decreases in tumor cells in comparison to nontumorous hepatocytes, with the exception of nuclear $\mathrm{HBx}$, which suggests that nuclear $\mathrm{HBx}$ plays a role in recurrence of well-differentiated and early-stage HCCs.

Key Words: Hepatitis B X protein; Hepatitis B surface antigens; Hepatitis B core antigens; Carcinoma, hepatocellular
Hepatocellular carcinoma (HCC) is the third most fatal cancer worldwide and poses a major burden to the healthcare system. ${ }^{1}$ More than $50 \%$ of HCC cases overall and $70 \%-80 \%$ of $\mathrm{HCC}$ cases in hepatitic B virus (HBV)-endemic regions are attributable to chronic HBV infection. ${ }^{2}$ The mechanism of viral hepatitis-mediated induction of HCC involves the direct mutagenic effect of the virus on the host genome and the indirect effect of the inflammation-necrosis regeneration cycle in the setting of chronic hepatitis. ${ }^{3}$

HBV is a member of the Hepadnaviridae family and has four important viral proteins: hepatitis B virus surface antigen (HB$s \mathrm{Ag}$ ), hepatitis $\mathrm{B}$ virus core antigen $(\mathrm{HBcAg})$, hepatitis $B$ virus $\mathrm{X}$ protein $(\mathrm{HBx})$, and viral DNA polymerase. $\mathrm{HBsAg}$ and $\mathrm{HB}-$ $\mathrm{cAg}$ are structural proteins that are the main components of the viral capsule and core. These proteins induce an immune re- sponse in infected hosts and can be used for the assessment of viral replication activity. Thus, they serve as clinical markers for diagnosis and follow-up of viral hepatitis patients via serum tests. ${ }^{4} \mathrm{HBx}$ is a key regulatory nonstructural protein of the virus that is at the intersection of HBV infection, replication, pathogenesis, and carcinogenesis. ${ }^{5}$

Integration of viral genomes in the host genome is considered a possible mechanism of hepatocarcinogenesis, and this notion is supported by the observation that a large portion of HCC have integrated HBV sequence encoding $\mathrm{HBx}$ and a truncated pre-S2/S protein. ${ }^{6} \mathrm{HBx}$ protein regulates the cell cycle and DNA repair genes of host cells and induces cellular transformation via transactivation (protein interactions) in the nucleus and cytoplasm. ${ }^{5}$

Clinically, a high viral load of HBV is associated with HCC 
recurrence, and early antiviral treatment can increase diseasefree survival (DFS) and overall survival of HCC patients. ${ }^{7,8} \mathrm{~A}$ specific mutated form of HBV known as genotype $C$ was reported to be associated with HCC occurrence in cirrhotic patients. $\mathrm{HBsAg}$ positivity in non-neoplastic liver tissue was reported as a risk factor for HCC recurrence. ${ }^{10}$

HBsAg expression is generally lower in tumor cells compared with adjacent non-neoplastic hepatocytes, and the HBx protein expression in non-neoplastic hepatic parenchyma is associated with the development of HCC in patients with chronic viral hepatitis. ${ }^{11,12}$ Previous studies of the expression of HBV genes and HBx protein in HCC and adjacent non-neoplastic hepatic parenchyma generally focused on the mechanisms underlying the HBV-related hepatocarcinogenesis.

The aim of this study was to assess the expression of the HBsAg, $\mathrm{HBcAg}$, and HBx proteins in HCC and nontumorous liver tissue and to examine the histologic features of HCCs, possible correlations with hepatitis serum markers, and their influence on cancer prognosis.

\section{MATERIALS AND METHODS}

\section{Patients and clinicopathologic parameters}

We enrolled $328 \mathrm{HBV}$ hepatitis patients who had been diagnosed with HCC based on a resected specimen and whose medical records and formalin-fixed paraffin blocks of tumor tissue were available from the archives of the Department of Pathology at Seoul National University Hospital (SNUH) from 1998 to 2004. We excluded co-infected hepatitis $C$ virus hepatitis patients and patients who had neither serologic nor clinical evidence of HBV infection. The matched non-neoplastic hepatic parenchyma was available for 155 of the 328 patients. Clinical information, such as age, sex, surgical procedure, underlying etiology of liver disease, preoperative serum $\alpha$-fetoprotein (AFP, $\mu \mathrm{g} / \mathrm{mL}$ ), preoperative treatment, and postoperative tumor recurrence, was collected from the medical records. Serological results of HBsAg, anti-HBs (HBsAb), IgG anti-HBc (HBcAb), hepatitis $B$ virus e antigen ( $\mathrm{HBeAg}$ ), and anti-HBe (HBeAb) were based on the most recent preoperative tests from medical records. Depending on the state of the serum viral marker, liver function test, and clinical symptom of hepatic failure or portal hypertension (e.g., hypoalbuminemia, prolonged prothrombin time, ascites, hyperbilirubinemia, or hepatic encephalopathy), "asymptomatic carriers" had positive serum viral markers, but a normal liver function test and no clinical symptom of hepatic failure, while "noncirrhotic" patients had positive serum viral marker with abnormal liver function test, but no symptom of hepatic failure. Patients with symptom of hepatic failure were assigned to the cirrhotic patient group. Disease recurrence was defined as newly appearing lesions diagnosed by radiologic examinations such as ultrasonography and X-ray computed tomography, or based on serum tumor markers such as AFP, after an operation. Pathologic information, such as tumor size, number of tumors, gross type (vaguely nodular, expanding nodular, nodular with perinodal extension, and multinodular confluent), angioinvasion, large vessel invasion, Edmondson-Steiner (ES) nuclear grade, histologic pattern of the tumor, cellular type of tumor cells (hepatic vs. non-hepatic including giant, pleomorphic, spindle, and clear cell types), and extent of tumor invasion, was collected from pathology reports and review of the slides. Criteria for pathologic T stage ( $\mathrm{pT}$ ) followed the liver tumor staging of the American Joint Committee on Cancer, seventh edition. ${ }^{13}$ Clinicopathologic parameters were assessed according to the general rules for examining primary liver cancer. ${ }^{14}$

Of the 328 patients, 283 were male and 45 were female (M:F ratio of 6.3:1), with a median age of 55 years (range, 25 to 80 years). The mean size of a tumor was $5.44 \mathrm{~cm}$ (range, 0.8 to 24.0 $\mathrm{cm})$. Most patients $(92.1 \%, 302 / 328)$ had undergone partial hepatectomy, such as right or left lobectomy, caudate lobectomy, or segmentectomy, whereas the remaining patients $(7.9 \%$, 26/328) had undergone total hepatectomy for transplantation. Follow-up periods ranged from 0 to 161 months (median, 51 months). This study was approved by the Institutional Review Board of Seoul National University Hospital (H-1011-046-339).

\section{Tissue microarray construction}

Hematoxylin and eosin slides were reviewed, and one representative formalin-fixed paraffin-embedded (FFPE) archival block was selected for each case. Each core tissue biopsy ( $2 \mathrm{~mm}$ in diameter) was taken from individual FFPE blocks (donor blocks) and arranged in recipient paraffin blocks (tissue array blocks) using a trephine. Immunohistochemical studies were performed on 13 array blocks containing 328 HCC samples and on six array blocks containing 155 samples of HCC-adjacent non-neoplastic tissue as a healthy control (Superbiochips Laboratories, Seoul, Korea). Each tissue microarray had four cores of normal liver, normal bile duct, and normal gastrointestinal tract mucosa as a negative control.

\section{Immunohistochemistry and interpretation}

Sections $(4 \mu \mathrm{m})$ were stained for HBcAg (1:800, hepatitis B core antigen rabbit polyclonal antibody, Cat. No. B0586, DAKO, 
Copenhagen, Denmark), HBsAg (1:200, HBsAg mouse monoclonal antibody, clone number S1-210, Cell Marque, Rocklin, CA, USA), and HBx (1:100, HBx mouse monoclonal antibody, clone number 3F6-G10, Thermo, Rockford, IL, USA) after antigen retrieval using a microwave and $\mathrm{pH} 6.0$ citrate buffer. The slides were stained according to methods specified in the Ultravision LP kit (Lab Vision, Fremont, CA, USA) or the Envision kit (Dako, Glostrup, Denmark) using the Bond polymer Refine Detection kit (Leica, Wetzlar, Germany). Unequivocal cytoplasmic staining for HBsAg in more than $5 \%$ of tumor cells was considered positive, and unequivocal nuclear and cytoplasmic staining for $\mathrm{HBcAg}$ in more than $5 \%$ of tumor cells was considered positive as described in a previous study. ${ }^{4}$ For HBx, both cytoplasmic and nuclear staining were observed in tumorous and nontumorous liver tissue; thus, we separately assessed the cytoplasmic and nuclear expression of HBx. The intensity of cytoplasmic staining was graded as weak, moderate, or strong by two pathologist (H.Y.Jung and K.-B.Lee), and a grade higher than moderate was considered as positive criteria. Nuclear staining was assessed by image analysis of digitally scanned slides $(\mathrm{Nu}-$ clear V9 algorithm, ScanScope, Aperio Technologies, Vista, CA, USA). The intensity of nuclear staining was graded as $1+$ (intensity range, 230 to 210 ), $2+$ (intensity range, 210 to 188 ), or $3+$ (intensity range, 188 to 162 ), and more than $5 \%$ of tumor cells with more than $2+$ intensity were considered as positive criteria.

\section{Statistical analysis}

Comparative analysis of $\mathrm{HBsAg}, \mathrm{HBcAg}$, and $\mathrm{HBx}$ expression with clinicopathologic parameters was assessed using the chisqaure test. Survival analysis was performed using the KaplanMeier method. The results were considered statistically significant when p-values were $<.05$. All calculations were performed using the PASW statistics ver. 18.0 (SPSS Inc., Chicago, IL, USA).

\section{RESULTS}

\section{Positive rates of $\mathrm{HBsAg}, \mathrm{HBcAg}$, and $\mathrm{HBx}$ expression in} $\mathrm{HCC}$

The representative immunohistochemical stainings and expression rates of $\mathrm{HBs} \mathrm{Ag}, \mathrm{HBcAg}$, and $\mathrm{HBx}$ in the nucleus and cytoplasm are summarized in Table 1 and Fig. 1, respectively. Among the 328 patients with $\mathrm{HBV}$, the positive rate for $\mathrm{HBsAg}$ was significantly lower in HCC than in nontumorous tissue (7.3\% vs $57.4 \%$, respectively; $\mathrm{p}<.001$ ), and the positive rate for nuclear HBx was higher in HCC than in nontumorous tissue $(52.1 \%$ [171/328] vs 30.3\% [47/155], respectively; $\mathrm{p}<.001)$. Cytoplasmic HBx expression was less frequent in HCC samples than in nontumorous tissue $(43.3 \%$ [142/328] vs $81.3 \%$ [126/ 155], respectively; $\mathrm{p}<.001)$.

\section{Clinicopathologic characteristics of HBsAg-, HBcAg-, and HBx-expressing HCC}

The clinicopathologic features and expression of HBsAg, HBcAg, and HBx are summarized in Table 2. HBsAg-expressing HCCs had lower ES nuclear grade and lower pT stage than HCCs without HBsAg expression ( $\mathrm{p}<.001$ and $\mathrm{p}=.013$, respectively). $\mathrm{HBcAg}$ was more frequently expressed in well-differentiated HCCs (lower ES grade) and in HCCs without preoperative treatment, such as transarterial chemoembolization, radiofrequency ablation, or percutaneous ethanol injection, as well as in patients who had lower serum AFP $(\mathrm{p}=.018, \mathrm{p}=.037$, and $\mathrm{p}=.015$, respectively). Cytoplasmic expression of $\mathrm{HBx}$ was associated with similar features: lower ES nuclear grade, smaller tumor size, less frequent angioinvasion, lower $\mathrm{pT}$ stage, and a lower serum AFP level compared to HCCs not expressing cytoplasmic HBx ( $<<.05)$ (Table 2). Compared to $\mathrm{HBsAg}$ and $\mathrm{HBcAg}$, nuclear $\mathrm{HBx}$ was more frequently expressed in HCCs with higher ES grade and with large-vessel invasion $(\mathrm{p}=.008$, and $\mathrm{p}=.017$, respectively).

Table 1. The percentage of patients positive for HBV proteins in the hepatocellular carcinoma and non-tumorous liver

\begin{tabular}{llccc}
\hline & & Tumor $(\mathrm{n}=328)$ & Non-tumor $(\mathrm{n}=155)$ & p-value \\
\hline HBsAg & Negative & $304(92.7)$ & $66(42.6)$ & $<.001^{*}$ \\
& Positive & $24(7.3)$ & $89(57.4)$ & .632 \\
HBcAg & Negative & $292(89.0)$ & $141(91.0)$ & $14(9.0)$ \\
& Positive & $36(11.0)$ & $108(69.7)$ & $<.001^{*}$ \\
HBx_nu & Negative & $157(47.9)$ & $47(30.3)$ & $<.001^{*}$ \\
& Positive & $171(52.1)$ & $29(18.7)$ & $126(81.3)$ \\
\hline
\end{tabular}

Values are presented as number (\%).

HBV, hepatitis B virus; HBsAg, HBV surface antigen; HBcAg, HBV core antigen; HBX, HBV X protein; nu, nuclear staining; cyto, cytoplasmic staining. ${ }^{*} \mathrm{p}<.05$. 

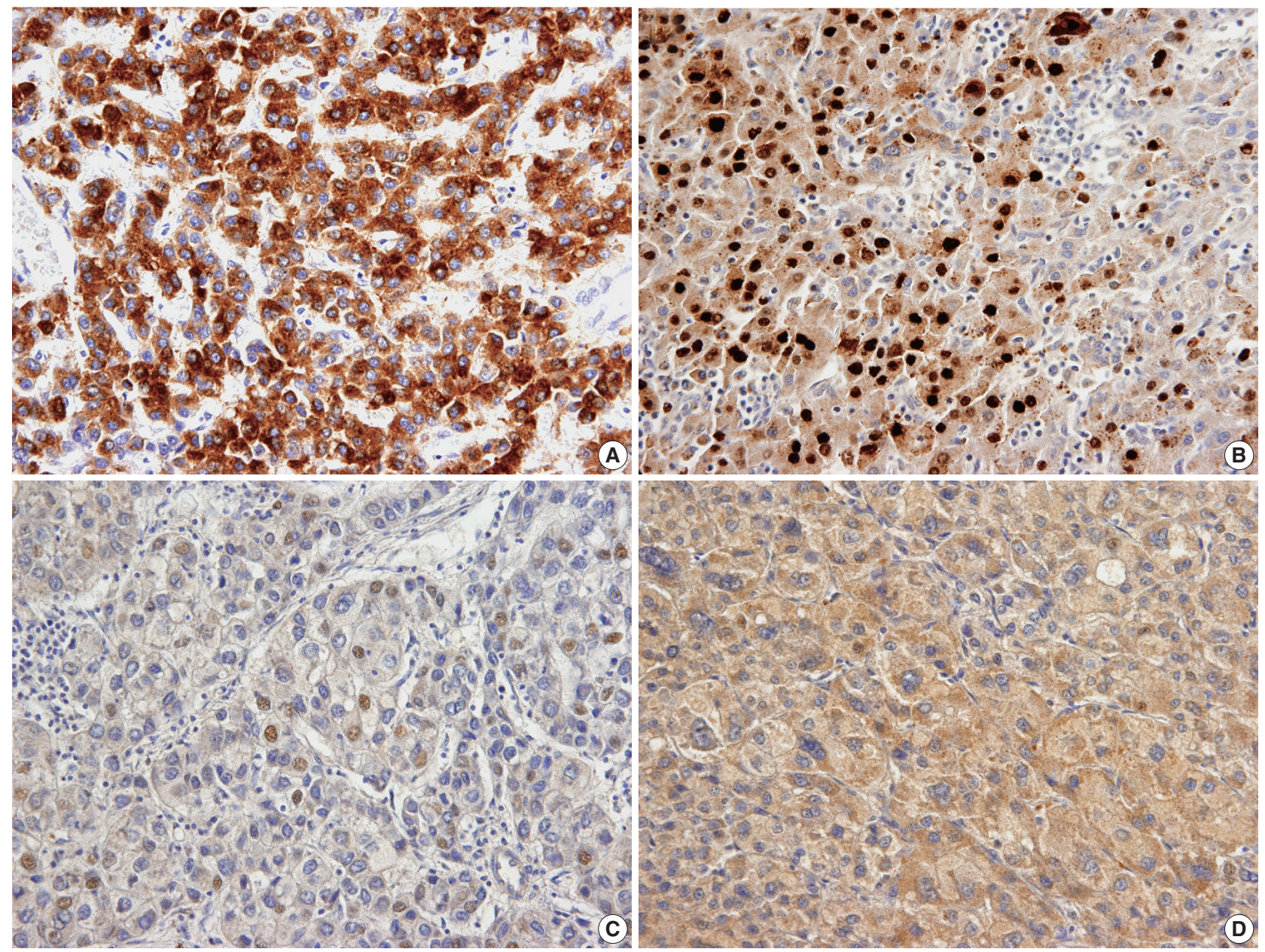

Fig. 1. Representative pictures of hepatitis B virus (HBV) surface antigen (HBsAg), HBV core antigen (HBcAg), and HBV X protein (HBx) proteins in hepatocellular carcinoma. Positive HBsAg (A), positive HBcAg (B), positive HBx in nuclei (C), and positive HBx (D) in the cytoplasm.

Although nuclear HBx was more frequently expressed in HCCs with high ES nuclear grade, the histologic pattern of HCCs with nuclear HBx expression was mostly trabecular and retained the hepatic cell type ( $\mathrm{p}=.002$ and $\mathrm{p}=.086$, respectively) (Table 2). Age and sex were not different between HBV protein positive groups and negative groups (data not shown).

\section{Correlation between serum hepatitis B markers and expression of HBV proteins in $\mathrm{HCC}$}

We set out to test whether the serum level of hepatitis B markers or the expression profile of nontumorous liver tissue showed any correlation with the expression of HBV proteins in HCCs. All patients with $\mathrm{HBs} A g$-positive HCCs were $\mathrm{HBsAg}$ positive in serum. Patients with positive serum HBeAb results showed lower positive rates of HBsAg in HCCs than did patients with negative serum HBeAb (10.8\% [7/65] vs 1.8\% [2/108], p =.027). Expression of $\mathrm{HBcAg}$ and expression of nuclear HBx in HCCs were not significantly concordant with the serum status of HBsAg, HBsAb, HBcAb, HBeAg, and HBeAb. As for the clinical stage of hepatitis, nuclear HBx was more frequently expressed in HCCs of noncirrhotic chronic hepatitis patients compared to asymptomatic carriers or cirrhotic patients (noncirrhotic vs asymptomatic vs cirrhosis; $75 \%$ [15/20] vs $35 \%$ [13/37] vs $43.9 \%$ [54/123], $\mathrm{p}=.023)$.

Progression of $\mathrm{HBsAg-}, \mathrm{HBcAg-}$, and $\mathrm{HBx}$-expressing $\mathrm{HCC}$

To test whether the HBsAg, $\mathrm{HBcAg}$, or $\mathrm{HBx}$ status of tumors influences cancer progression, we analyzed DFS time after operation in the 328 patients with HBV-associated HCC using Kaplan-Meier analysis. We could not determine any correlation between DFS time and the expression status of $\mathrm{HBsAg}, \mathrm{HBcAg}$, and $\mathrm{HBx}$ in tumors and nontumorous tissue or the serum levels of hepatitis markers (data not shown). The size and multiplicity of the tumor, angioinvasion, ES nuclear grade, and the extent of 
Table 2. Clinicopathologic characteristics of hepatocellular carcinomas expressing HBV proteins

\begin{tabular}{|c|c|c|c|c|c|c|c|c|c|}
\hline \multirow[b]{2}{*}{ Variable } & \multicolumn{3}{|c|}{$\mathrm{HBsAg}$} & \multicolumn{2}{|c|}{$\mathrm{HBcAg}$} & \multicolumn{2}{|c|}{ HBx_nu } & \multicolumn{2}{|c|}{ HBx_cyto } \\
\hline & $\begin{array}{c}\text { No. } \\
(n=328)\end{array}$ & $\begin{array}{l}\text { Negative } \\
(n=304)\end{array}$ & $\begin{array}{l}\text { Positive } \\
(n=24)\end{array}$ & $\begin{array}{l}\text { Negative } \\
(n=292)\end{array}$ & $\begin{array}{l}\text { Positive } \\
(n=36)\end{array}$ & $\begin{array}{l}\text { Negative } \\
(n=157)\end{array}$ & $\begin{array}{l}\text { Positive } \\
(n=171)\end{array}$ & $\begin{array}{l}\text { Negative } \\
(n=186)\end{array}$ & $\begin{array}{l}\text { Positive } \\
(n=142)\end{array}$ \\
\hline \multicolumn{10}{|l|}{ Size $(\mathrm{cm})$} \\
\hline$\leq 3$ & 97 & 91 (29.9) & $6(25.0)$ & 85 (29.1) & $12(33.3)$ & $43(27.4)$ & $54(31.6)$ & $44(23.7)$ & $53(37.3)$ \\
\hline$>3$ & 231 & $213(70.1)$ & $18(75.0)$ & $207(70.9)$ & $24(66.7)$ & $114(72.6)$ & $117(68.4)$ & $142(76.3)$ & $89(62.7)$ \\
\hline$p$-value & & .401 & & .364 & & .239 & & $.005^{\star}$ & \\
\hline \multicolumn{10}{|l|}{ Angioinvasion } \\
\hline Absent & 167 & $151(49.7)$ & $16(66.7)$ & $148(50.7)$ & $19(52.8)$ & $82(52.2)$ & 85 (49.7) & $80(43.0)$ & $87(61.3)$ \\
\hline Present & 161 & $153(50.3)$ & $8(33.3)$ & $144(49.3)$ & 17 (47.2) & $75(47.8)$ & $86(50.3)$ & $106(57.0)$ & $55(38.7)$ \\
\hline$p$-value & & .109 & & .813 & & .648 & & $.001^{*}$ & \\
\hline \multicolumn{10}{|c|}{ Large vessel invasion } \\
\hline Absent & 312 & $288(94.7)$ & $24(100.0)$ & $277(94.9)$ & 35 (97.2) & $154(98.1)$ & $158(92.4)$ & $173(93.0)$ & 139 (97.9) \\
\hline Present & 16 & $16(5.3)$ & $0(0.0)$ & $15(5.1)$ & $1(2.8)$ & $3(1.9)$ & $13(7.6)$ & $13(7.0)$ & $3(2.1)$ \\
\hline$p$-value & & .618 & & 1.000 & & $.017^{\star}$ & & $.042^{\star}$ & \\
\hline \multicolumn{10}{|l|}{ ES nuclear grade } \\
\hline 1 & 30 & $21(6.9)$ & $9(37.5)$ & $22(7.5)$ & $8(22.2)$ & $21(13.4)$ & $9(5.3)$ & $10(5.4)$ & $20(14.1)$ \\
\hline 2 & 170 & 159 (52.3) & $11(45.8)$ & $151(51.7)$ & 19 (52.8) & 83 (52.9) & 87 (50.9) & $96(51.6)$ & $74(52.1)$ \\
\hline 3 & 120 & 116 (38.2) & $4(16.7)$ & 111 (38.0) & $9(25.0)$ & 47 (29.9) & $73(42.7)$ & 74 (39.8) & 46 (32.4) \\
\hline 4 & 8 & $8(2.6)$ & $0(0.0)$ & $8(2.7)$ & $0(0.0)$ & $6(3.8)$ & $2(1.2)$ & $6(3.2)$ & $2(1.4)$ \\
\hline$p$-value & & $<.001$ & & .018 & & $.008^{*}$ & & $.008^{\star}$ & \\
\hline \multicolumn{10}{|l|}{ Histologic pattern } \\
\hline Trabecular & 294 & 272 (89.5) & $22(91.7)$ & $260(89.0)$ & $34(94.4)$ & $132(84.1)$ & $162(94.7)$ & $168(90.3)$ & $126(88.7)$ \\
\hline Nontrabecular & 34 & $32(10.5)$ & $2(8.3)$ & $32(11.0)$ & $2(5.6)$ & 25 (15.9) & $9(5.3)$ & $18(9.7)$ & $16(11.3)$ \\
\hline$p$-value & & .734 & & .316 & & $.002^{\star}$ & & .640 & \\
\hline \multicolumn{10}{|l|}{ Cellular type } \\
\hline Hepatic & 312 & $289(95.1)$ & $23(95.8)$ & $280(95.9)$ & 32 (88.9) & $146(93.0)$ & $166(97.1)$ & $174(93.5)$ & 138 (97.2) \\
\hline Nonhepatic & 16 & $15(4.9)$ & $1(4.2)$ & $12(4.1)$ & $4(11.1)$ & $11(7.0)$ & $5(2.9)$ & $12(6.5)$ & $4(2.8)$ \\
\hline$p$-value & & .867 & & .085 & & .086 & & .130 & \\
\hline \multicolumn{10}{|l|}{ pT (AJCC 7th ed) } \\
\hline 1 & 132 & 117 (38.5) & 15 (62.5) & $120(41.1)$ & 12 (33.3) & $62(39.5)$ & 70 (40.9) & 66 (35.5) & $66(46.5)$ \\
\hline 2 & 137 & $129(42.4)$ & $8(33.3)$ & $117(40.1)$ & 20 (55.6) & 68 (43.3) & 69 (40.4) & 79 (42.5) & $58(40.8)$ \\
\hline 3 & 42 & $41(13.5)$ & $1(4.2)$ & 39 (13.4) & $3(8.3)$ & $20(12.7)$ & 22 (12.9) & 30 (16.1) & $12(8.5)$ \\
\hline 4 & 17 & $17(5.6)$ & $0(0.0)$ & $16(5.5)$ & $1(2.8)$ & $7(4.5)$ & $10(5.8)$ & $11(5.9)$ & $6(4.2)$ \\
\hline$p$-value & & $.013^{\star}$ & & .334 & & .914 & & $.019^{\star}$ & \\
\hline \multicolumn{10}{|c|}{ Preoperative treatment } \\
\hline Not done & 203 & 189 (62.2) & $14(58.3)$ & $175(59.9)$ & $28(77.8)$ & 93 (59.2) & $110(64.3)$ & $106(57.0)$ & $97(68.3)$ \\
\hline Done & 125 & $115(37.8)$ & $10(41.7)$ & $117(40.1)$ & $8(22.2)$ & $64(40.8)$ & $61(35.7)$ & $80(43.0)$ & $45(31.7)$ \\
\hline$p$-value & & .709 & & $.037^{\star}$ & & .343 & & $.036^{\star}$ & \\
\hline \multicolumn{10}{|c|}{ Serum AFP $(\mu \mathrm{g} / \mathrm{mL})$} \\
\hline$\leq 20.0$ & 187 & $170(55.9)$ & $17(70.8)$ & $160(54.8)$ & $27(75.0)$ & $83(52.9)$ & $104(60.8)$ & $92(49.5)$ & $95(66.9)$ \\
\hline$>20.0$ & 141 & $134(44.1)$ & $7(29.2)$ & $132(45.2)$ & $9(25.0)$ & $74(47.1)$ & 67 (39.2) & $94(50.5)$ & $47(33.1)$ \\
\hline$p$-value & & .113 & & $.015^{\star}$ & & .090 & & $.001^{*}$ & \\
\hline
\end{tabular}

Values are presented as number (\%).

HBV, hepatitis B virus; HBsAg, HBV surface antigen; HBcAg, HBV core antigen; HBX, HBV X protein; nu, nuclear staining; cyto, cytoplasmic staining; ES, Edmondson-Steiner; AJCC, American Joint Committee on Cancer; AFP, $\alpha$-fetoprotein.

${ }^{*} p<.05$.

tumor invasion were statistically significant prognostic factors for tumor recurrence in the entire sample of 328 patients (data not shown). The low frequency of positive HBsAg in HCCs and well-differentiated histology of HBsAg-expressing HCCs may be a confounder of the above-mentioned negative results in the entire group, so we stratified the study group and analyzed pro- gression-free survival in 99 patients with early-stage (pT1) and well-differentiated HCC (ES nuclear grade 1 and 2); these patients were a relatively low-risk group for HCC recurrence. In $48.5 \%$ (48/99) of the patients, the tumor recurred and median DFS time was 84 months, ranging from 2 to 153 months. As shown in Table 3, nuclear HBx in tumors was a statistically sig- 
Table 3. Disease-free survival analysis of 99 pT1 and well-differentiated HBV-related HCCs in relation to the expression of HBV proteins

\begin{tabular}{|c|c|c|c|c|}
\hline & & Recurrence rate & Median DFS (mo) & $\mathrm{p}$-value \\
\hline \multicolumn{5}{|l|}{ Tumor (n=99) } \\
\hline $\mathrm{HBsAg}$ & $(-)$ vs $(+)$ & $38 / 84$ (45.2\%) vs $10 / 15$ (66.7\%) & 126 vs 35 & .095 \\
\hline $\mathrm{HBcAg}$ & $(-)$ vs $(+)$ & $44 / 88(50.0 \%)$ vs $4 / 11$ (36.4\%) & 84 vs NA & .619 \\
\hline HBx_nu & $(-)$ vs $(+)$ & $20 / 51$ (39.2\%) vs $28 / 48$ (58.3\%) & 126 vs 35 & $.015^{\star}$ \\
\hline HBx_cyto & $(-)$ vs $(+)$ & $22 / 46(47.8 \%)$ vs $26 / 53(49.1 \%)$ & 126 vs 61 & .541 \\
\hline \multicolumn{5}{|c|}{ Nontumorous tissue $(n=45)$} \\
\hline HBsAg & $(-)$ vs $(+)$ & $8 / 18$ (44.4\%) vs $16 / 27$ (59.3\%) & 135 vs 21 & .379 \\
\hline $\mathrm{HBcAg}$ & $(-)$ vs (+) & $22 / 41$ (53.7\%) vs 2/4 (50.0\%) & 135 vs 7 & .805 \\
\hline HBx_nu & $(-)$ vs $(+)$ & $17 / 31$ (54.8\%) vs 7/14 (50.0\%) & 135 vs 33 & .870 \\
\hline HBx_cyto & $(-)$ vs (+) & $5 / 10(50.0 \%)$ vs $19 / 35$ (54.3\%) & 33 vs 135 & .837 \\
\hline \multicolumn{5}{|l|}{ Serum } \\
\hline HBsAg $(n=98)$ & $(-)$ vs $(+)$ & $3 / 11$ (27.3\%) vs 44/87 (50.6\%) & 126 vs 84 & .296 \\
\hline HBsAb (n=94) & $(-)$ vs $(+)$ & $32 / 74(43.2 \%)$ vs $11 / 20$ (55.0\%) & 126 vs 35 & .163 \\
\hline $\mathrm{HBcAb}(\mathrm{n}=37)$ & $(-)$ vs (+) & $2 / 4$ (50.0\%) vs $13 / 33$ (39.4\%) & 7 vs 84 & .473 \\
\hline $\mathrm{HBeAg}(\mathrm{n}=55)$ & $(-)$ vs $(+)$ & $19 / 41$ (46.3\%) vs 6/14 (42.9\%) & 84 vs 153 & .505 \\
\hline $\mathrm{HBeAb}(\mathrm{n}=51)$ & $(-)$ vs $(+)$ & $12 / 21(57.1 \%)$ vs $12 / 30(40.0 \%)$ & 33 vs 84 & .406 \\
\hline
\end{tabular}

HBV, hepatitis B virus; HCC, hepatocellular carcinoma; DFS, disease-free survival; HBsAg, HBV surface antigen; HBcAg, HBV core antigen; NA, not applicable; HBx, HBV X protein; nu, nuclear staining; cyto, cytoplasmic staining; HBsAb, anti-HBs; HBcAb, lgG anti-HBc; HBeAg, hepatitis B virus e antigen; HBeAb, anti-HBe.

${ }^{*} \mathrm{p}<.05$.

nificant prognostic factor $(\mathrm{p}=.015)$, whereas the presence of HBsAg in a tumor showed a tendency for poor prognosis of earlystage HCCs, but did not reach statistical significance $(\mathrm{p}=.095)$. Cytoplasmic expression of HBx in tumor and nontumorous tissue was not associated with tumor recurrence. In nontumorous liver tissue, $\mathrm{HBs} \mathrm{Ag}-$, $\mathrm{HBcAg}$-, and $\mathrm{HBx}-$ positive patients had a relatively lower median DFS, but this effect was statistically insignificant (log-rank p > .05) (Table 3). The presence of HBsAg in the tumor, serum, and nontumorous tissue was correlated with shorter DFS and early recurrence compared to HBsAg-negative patients, as shown in Fig. 2, but this effect was not statistically significant (Table 3). Survival analysis for the high-risk group (advanced stages, pT2-4) or higher nuclear grade (ES nuclear grade 3 and 4) showed no significant difference in DFS according to the status of HBV-associated proteins in serum, tumor, and nontumor tissues (data not shown).

\section{DISCUSSION}

In this study, we found that the expression of HBsAg, representing normal viral replication in infected cells, is less frequent in tumors than nontumorous hepatocytes, and HBx, which is one of the key proteins in hepatocarcinogenesis, could be preferentially expressed in different subcellular compartments. The nuclear expression of $\mathrm{HBx}$ occurs more frequently in tumors than in nontumorous hepatocytes, whereas the cytoplasmic expression of $\mathrm{HBx}$ is less frequent in tumors, according to our results. HCCs with pronounced expression of $\mathrm{HBs} \mathrm{Ag}$ have well-differentiated histology, but HCCs with nuclear expression of HBx showed increased nuclear atypia and aggressive behavior. When the test group is restricted to well-differentiated and to early-stage tumors to minimize the influence of tumor-related prognostic factors, then HCCs expressing nuclear HBx proteins show a higher risk of early recurrence after operation.

Persistence of HBx is important for the pathogenesis of early HCC development, and HBx expression in the liver during chronic $\mathrm{HBV}$ infection may be an important prognostic marker for the development of HCC., ${ }^{5,12}$ Even seronegative HBV patients have HBx gene and protein expression in HCC, which are consistent with the hepatocarcinogenic properties of $\mathrm{HBx} .{ }^{15}$ The subcellular location of $\mathrm{HBx}$, as assessed by immunohistochemistry in previous studies, is generally in the cytoplasm of hepatocytes or tumor cells and is consistent with the biological functions of $\mathrm{HBx}$, i.e., protein-protein interactions in cytoplasmic signaling pathways. ${ }^{5}$ The biological role of $\mathrm{HBx}$ in the nucleus may involve direct interaction with DNA, RNA, or transcription factors, but the existing data are scarce. Recently, it was shown in an in vitro study using a human cell line that when HBx is targeted to the nucleus by a nuclear localization signal, it can restore $\mathrm{HBx}$-deficient $\mathrm{HBV}$ replication, whereas $\mathrm{HBx}$ containing a nuclear export signal cannot, suggesting that nuclear localization of HBx is required for viral replication. ${ }^{16}$ In addition, chipbased chromatin immunoprecipitation with expression microarray profiling for HCCs identified 184 gene targets that might 

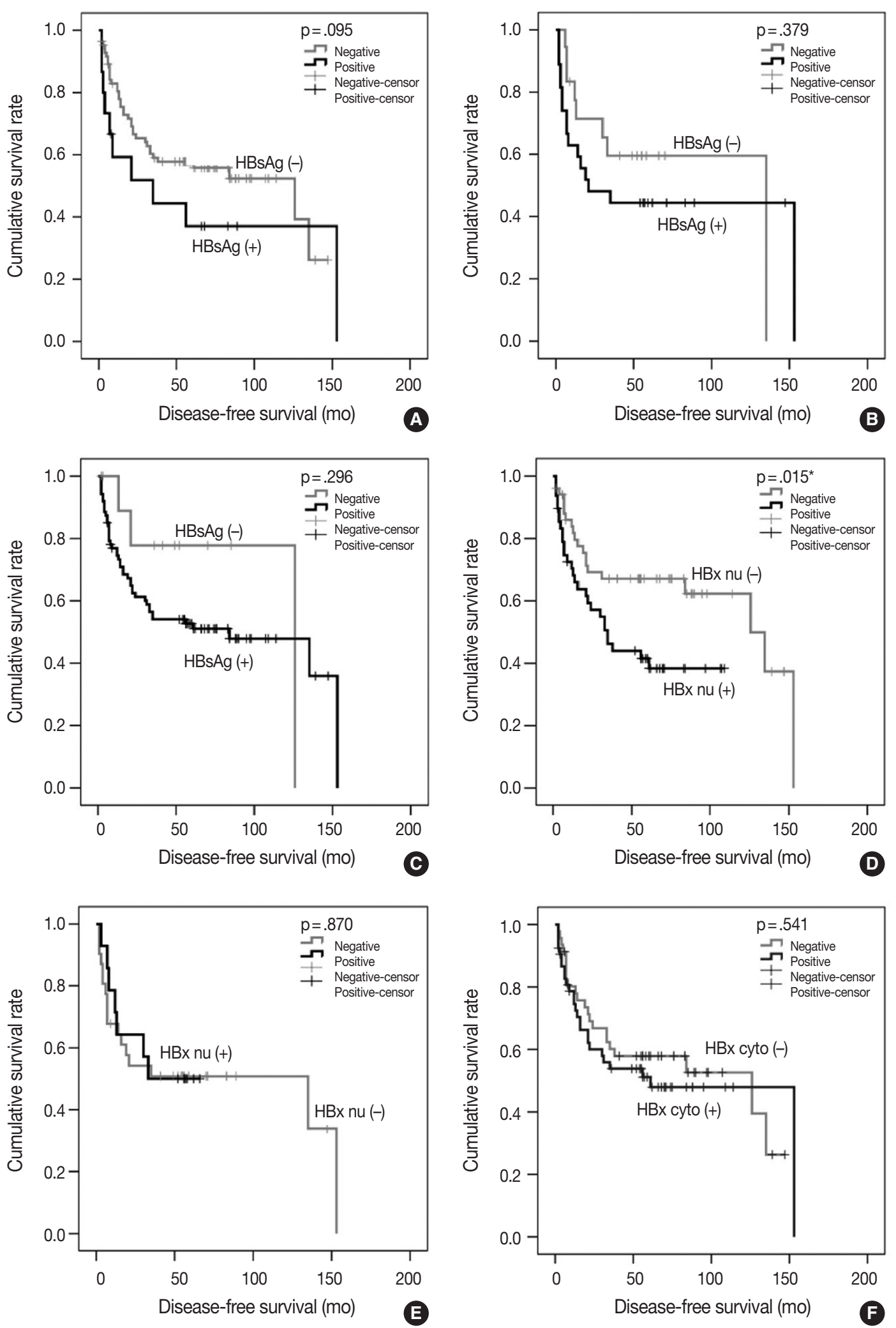

Fig. 2. Cumulative disease-free survival curves of 99 patients with $\mathrm{pT} 1$ and well-differentiated hepatocellular carcinoma in relation to the presence of hepatitis $B$ virus (HBV) surface antigen ( $\mathrm{HBs} A g$ ) and $\mathrm{HBV} X$ protein $(\mathrm{HBX})$ in a tumor, nontumorous tissue, and serum. $\mathrm{HBs} A g$ in tumors (A), HBsAg in nontumorous tissue (B), HBsAg in serum (C), nuclear HBx (HBx nu) in tumors (D), HBX nu in nontumorous tissues (E), and cytoplasmic $\mathrm{HBx}$ (HBx cyto) (F) in tumors. ${ }^{*} \mathrm{p}<.05$. 
be directly deregulated by $\mathrm{HBx}$ via targeting from indirect protein-DNA binding as well as transcriptional factors directly interacting with $\mathrm{HBx} .^{17}$

Our results show that nuclear, not cytoplasmic, HBx expression correlates with aggressiveness of HCC tumors, such as nuclear grade or large vessel invasion, and with early recurrence after an operation. These data suggest that the interaction of $\mathrm{HBx}$ with nuclear proteins might be more important for tumor progression than for cytoplasmic interactions of $\mathrm{HBx}$. Although the HBx protein may be involved in metastasis and tumor invasiveness by regulating proteins that control the extracellular matrix, angiogenesis, or epithelial mesenchymal transition, the reason for the paucity of clinical evidence regarding the HBx protein and HCC recurrence or prognosis could be the difficulties with interpretation of HBx immunohistochemistry. ${ }^{18-21}$ In the majority of the studies on $\mathrm{HBx}$, cytoplasmic staining was considered positive expression, and nuclear staining was not investigated. ${ }^{15,18,19,22}$ Because we minimized the influence of wellknown prognostic factors, such as vascular invasion, size, multiplicity, extent of tumor invasion, and differentiation, by selecting HCCs of pT1 stage and ES nuclear grade 1 and 2, we expected that HBx in nontumorous tissue would be a prognostic factor, but the results showed that it was not. We tried to find a link between the pattern of recurrence and the HBx expression, but the recurrence pattern (presented as a single intrahepatic mass versus multiple or disseminated intrahepatic or extrahepatic masses) was not different depending on the HBx expression in tumor and non-tumor tissues. However, nuclear $\mathrm{HBx}(-)$ HCCs both in tumor and nontumor were more frequently presented as a single intrahepatic mass at recurrence time after resection (rate of a single intrahepatic mass, $\mathrm{HBx} \_n u[+]$ in tumor and non-tumor vs HBx_nu[+] in tumor or non-tumor $59.3 \%$ [16/27] vs $37.0 \%$ [27/73], $\mathrm{p}=.388$ ), but this result was not statistically significant. Further research is needed to understand how nuclear expression of HBx promotes tumor recurrence before pathologic features of tumor aggressiveness have appeared.

The mechanism of HCC recurrence in HBV patients is regrowth of microscopically or macroscopically leftover tumor cells or de novo occurrence of HCC. The viral influence on HCC recurrence can be explained by the de novo tumor recurrence. Su et al. ${ }^{23}$ reported that a higher serum HBV DNA load was an important risk factor associated with recurrence in patients with HBVassociated HCC without antiviral therapy after resection, but this observation was not applicable in advanced stage HCC. Tsai et al. ${ }^{10}$ reported that a ground-glass hepatocyte pattern or $\mathrm{HBsAg}$ expression in nontumorous liver tissues was a prognos- tic marker for the recurrence of HBV-related HCC after hepatic resection; these data also support the viral influence on HCC recurrence. Our finding that HBsAg-expressing HCCs recur earlier than do HBsAg-negative HCCs in patients with early-stage and well-differentiated HCC is in line with the previous reports except for the source of HBsAg production, although this finding was not statistically significant.

Last, our results were limited due to the one core-construct of the tissue microarrays that were used. However, staining on full sections for preliminary study showed that staining pattern was relatively patched, but generally weak to moderate areas were alternatively mixed with strongly stained areas, not totally negative areas, and the size of the study groups $(\mathrm{n}=483)$ might be large enough to compensate this problem.

In summary, we report that nuclear expression of $\mathrm{HBx}$ in HBV-associated HCCs increases in tumors compared to nontumorous tissue, and HBsAg-expressing HCCs have a tendency to recur early, even if they are well-differentiated histologically and the surgical procedure is performed at an early stage. Tissue expression of $\mathrm{HBsAg}$ was correlated with serum HBsAg. Nuclear expression of $\mathrm{HBx}$ in tumor tissue assessed by immunohistochemistry can be a useful prognostic marker for prediction of tumor recurrence in early-stage HCC patients and may ultimately lead to novel therapeutic strategies for managing HBVassociated HCC and for researching HBV-associated hepatocarcinogenesis.

\section{Conflicts of Interest}

No potential conflict of interest relevant to this article was reported.

\section{Acknowledgments}

This research was supported by a grant of the Korea Health Technology R\&D Project through the Korea Health Industry Development Institute (KHIDI), funded by the Ministry of Health \& Welfare, Republic of Korea (grant number: HI14C3298).

\section{REFERENCES}

1. Ferlay J, Shin HR, Bray F, Forman D, Mathers C, Parkin DM. Estimates of worldwide burden of cancer in 2008: GLOBOCAN 2008. Int J Cancer 2010; 127: 2893-917.

2. Nordenstedt H, White DL, El-Serag HB. The changing pattern of epidemiology in hepatocellular carcinoma. Dig Liver Dis 2010; 42 Suppl 3: S206-14. 
3. Brechot C, Jaffredo F, Lagorce D, et al. Impact of HBV, HCV and GBV-C/HGV on hepatocellular carcinomas in Europe: results of a European concerted action. J Hepatol 1998; 29: 173-83.

4. Theise ND, Bodenheimer HC Jr, Ferrell LD. Acute and chronic viral hepatitis. In: Burt AD, Portmann BC, Ferrell LD, eds. MacSween's pathology of the liver. 6th ed. Edinburgh: Churchill Livingstone Elsevier, 2012; 361-401.

5. Ng SA, Lee C. Hepatitis B virus X gene and hepatocarcinogenesis. J Gastroenterol 2011; 46: 974-90.

6. Goodman ZD, Terraciano LM, Wee A. Tumours and tumour-like lesions of the liver. In: Burt A, Portmann B, Ferrell L, eds. MacSween's pathology of the liver. 6th ed. Edinburgh: Churchill Livingstone Elsevier, 2012; 761-851.

7. Xia F, Lai EC, Lau WY, et al. High serum hyaluronic acid and HBV viral load are main prognostic factors of local recurrence after complete radiofrequency ablation of hepatitis B-related small hepatocellular carcinoma. Ann Surg Oncol 2012; 19: 1284-91.

8. Huang G, Yang Y, Shen F, et al. Early viral suppression predicts good postoperative survivals in patients with hepatocellular carcinoma with a high baseline HBV-DNA load. Ann Surg Oncol 2013; 20: 1482-90.

9. Yin J, Xie J, Liu S, et al. Association between the various mutations in viral core promoter region to different stages of hepatitis B, ranging of asymptomatic carrier state to hepatocellular carcinoma. Am J Gastroenterol 2011; 106: 81-92.

10. Tsai HW, Lin YJ, Lin PW, et al. A clustered ground-glass hepatocyte pattern represents a new prognostic marker for the recurrence of hepatocellular carcinoma after surgery. Cancer 2011; 117: 2951-60.

11. Kremsdorf D, Soussan P, Paterlini-Brechot P, Brechot C. Hepatitis B virus-related hepatocellular carcinoma: paradigms for viral-related human carcinogenesis. Oncogene 2006; 25: 3823-33.

12. Zhu M, London WT, Duan LX, Feitelson MA. The value of hepatitis $\mathrm{B} x$ antigen as a prognostic marker in the development of hepatocellular carcinoma. Int J Cancer 1993; 55: 571-6.

13. Edge SB, Compton CC. The American Joint Committee on Cancer: the 7th edition of the AJCC cancer staging manual and the future of TNM. Ann Surg Oncol 2010; 17: 1471-4.
14. The general rules for the clinical and pathological study of primary liver cancer. Liver Cancer Study Group of Japan. Jpn J Surg 1989; 19: 98-129.

15. Shiota G, Oyama K, Udagawa A, et al. Occult hepatitis B virus infection in HBs antigen-negative hepatocellular carcinoma in a Japanese population: involvement of HBx and p53. J Med Virol 2000; 62: 151-8.

16. Keasler VV, Hodgson AJ, Madden CR, Slagle BL. Hepatitis B virus $\mathrm{HBx}$ protein localized to the nucleus restores $\mathrm{HBx}$-deficient virus replication in HepG2 cells and in vivo in hydrodynamically-injected mice. Virology 2009; 390: 122-9.

17. Sung WK, Lu Y, Lee CW, Zhang D, Ronaghi M, Lee CG. Deregulated direct targets of the hepatitis $\mathrm{B}$ virus (HBV) protein, $\mathrm{HBx}$, identified through chromatin immunoprecipitation and expression microarray profiling. J Biol Chem 2009; 284: 21941-54.

18. Ou DP, Tao YM, Tang FQ, Yang LY. The hepatitis B virus X protein promotes hepatocellular carcinoma metastasis by upregulation of matrix metalloproteinases. Int J Cancer 2007; 120: 1208-14.

19. Xie H, Song J, Liu K, et al. The expression of hypoxia-inducible factor-1alpha in hepatitis B virus-related hepatocellular carcinoma: correlation with patients' prognosis and hepatitis B virus $\mathrm{X}$ protein. Dig Dis Sci 2008; 53: 3225-33.

20. Xia L, Huang W, Tian D, et al. Upregulated FoxM1 expression induced by hepatitis $\mathrm{B}$ virus $\mathrm{X}$ protein promotes tumor metastasis and indicates poor prognosis in hepatitis $B$ virus-related hepatocellular carcinoma. J Hepatol 2012; 57: 600-12.

21. Liu $\mathrm{H}, \mathrm{Xu} \mathrm{L}, \mathrm{He} H$, et al. Hepatitis B virus X protein promotes hepatoma cell invasion and metastasis by stabilizing Snail protein. Cancer Sci 2012; 103: 2072-81.

22. Zhang X, Dong N, Zhang H, You J, Wang H, Ye L. Effects of hepatitis $B$ virus $X$ protein on human telomerase reverse transcriptase expression and activity in hepatoma cells. J Lab Clin Med 2005; 145: 98-104.

23. Su CW, Chiou YW, Tsai YH, et al. The influence of hepatitis B viral load and pre-S deletion mutations on post-operative recurrence of hepatocellular carcinoma and the tertiary preventive effects by anti-viral therapy. PLoS One 2013; 8: e66457. 